\title{
Fractional domination for two classes of graphs
}

\author{
Baogen Xu, Yan Zou, Lixin Zhao \\ School of Natural Science, East China Jiaotong University, Nanchang, 330013, China
}

Email address:

Baogenxu@163.com. (Baogen Xu)

\section{To cite this article:}

Baogen Xu, Yan Zou, Lixin Zhao. Fractional Domination for Two Classes of Graphs. Pure and Applied Mathematics Journal. Vol. 3, No. 6, 2014, pp. 137-139. doi: 10.11648/j.pamj.20140306.15

\begin{abstract}
Let be a graph, a real-valued function is said to be a dominating of $\mathrm{G}$ if holds for every vertex, the fractional domination function number is defined as, and the fractional total domination function number of $G$ is analogous. In this paper we research the fractional domination problem for two classes of special graphs, obtained the fractional domination numbers of the generalized star graphs and the fractional total domination function numbers of the generalized wheel graphs.
\end{abstract}

Keywords: Generalized Wheel Graph, Fractional Domination Function Number, Fractional Total Domination Number, Generalized Star Graph

\section{Introduction}

In this paper, the graphs are undirected simple graphs and for other terminologies we follow [1-3]. Let $G$ be a graph with vertex $V(G)$ and edge set $E(G)$, for any vertex $v \in V(G)$, the open and closed neighborhoods of $\mathrm{V}$ are denoted by $N(\mathrm{v})$ and $N[\mathrm{v}]=N(\mathrm{v}) \cup\{\mathrm{v}\}$, respectively.

For convenience, let $G=(V, E)$ be a graph, for a realvalued function $f: V \rightarrow[0,1]$ and $S \subseteq V$, we write $f(S)=\sum_{v \in S} f(v)$.

In recent years, the results have been more and more riched with the research of graph theories in growing numbers. G.S.Domke、S.T.Hedetniemi and R.C. Laskar ${ }^{[4]}$ first investgated the fractional domination, T.W.Haynes 、 S.T.Hedetniemi and P.J.Slater ${ }^{[5]}$ summarized the main results about the theory of domination in graphs. But so far there have been a few conclusions of the fractional domination in graphs while some special graphs have not been woked out.

Definition 1[1] Let $G=(V, E)$ be a simple graph. A realvalued function $f: V \rightarrow[0,1]$ is a fractional dominating function (simply denoting $F$-dominating function)of $G$ if $f(N[\mathrm{u}]) \geq 1$ holds for every vertex $\mathrm{u} \in V$. The fractional domination number, denoted $\gamma_{f}(G)$, is defined as follows:

$\gamma_{\mathrm{f}}(\mathrm{G})=\min \{\mathrm{f}(\mathrm{V}) \mid \mathrm{f}$ is a fractionaldominating function of $\mathrm{G}\}$.

A $F$-dominating function $f$ is minimal if $\gamma_{f}(G)=f(V)$.
Definition 2[1] Let $G=(V, E)$ be a simple graph without isolated vertices. A real-valued function $f: V \rightarrow[0,1]$ is a fractional total dominating function of $G$ if $f(N(\mathrm{u})) \geq 1$ holds for every vertex $\mathrm{u} \in V$. The fractional total domination number, denoted $\gamma_{f}^{0}(G)$, is defined as follows:

$\gamma_{f}^{0}(G)=\min \{f(V) \mid f$ is a fractional total dominating function of $\mathrm{G}\}$.

A fractional total dominating function $f$ is minimal if $\gamma_{f}^{0}(G)=f(V)$.

Definition 3[1] Let $G=(V, E)$ be a simple graph. A realvalued function $f: V \rightarrow[0,1]$ is a packing dominating function of $G$ if $f(N[\mathrm{u}]) \leq 1$ holds for every vertex $\mathrm{u} \in V$.

A packing function $f$ is maximal if for every $\mathrm{u} \in V$ with $f(\mathrm{u})<1$, there exists a vertex $\mathrm{v} \in N[\mathrm{u}]$ such that $f(\mathrm{~N}[\mathrm{v}]) \leq 1$.

The fractional packing number, $\mathrm{p}_{f}(\mathrm{G})$, and the upper fractional packing number, $P_{f}(G)$, are defined as follows:

$$
\begin{aligned}
& \mathrm{p}_{f}(G)=\min \{f(V) \mid f \text { is a maximal packing function of } \mathrm{G}\} \\
& P_{f}(G)=\max \{f(V) \mid f \text { is a maximal packing function of } \mathrm{G}\}
\end{aligned}
$$

Lemma 1[1] For every graph $G$, then $P_{f}(G)=\gamma_{f}(G)$. For a graph $G=(V, E)$ and a function $f: V \rightarrow[0,1]$, if $f(\mathrm{~N}[\mathrm{u}])=1$ holds if for every $\mathrm{u} \in V$, then $f$ are both maximal packing function and minimal $F$-dominating 
function. By the above Lemma 1, we have the following lemma.

Lemma 2 For every graph $G$ if $f$ is a $F$-dominating function of $G$, and $f(\mathrm{~N}[\mathrm{u}])=1$ holds for every $\mathrm{u} \in V$, then $\gamma_{f}(G)=f(V)$; Similarly, if $f$ is a fractional total dominating function of $G$, and $f(\mathrm{~N}(\mathrm{u}))=1$, then $\gamma_{f}^{0}(G)=f(V)$.

In this paper, by Lemma 2 , we give the fractional domination numbers of the generalized star graphs and the fractional total domination function numbers of the generalized wheel graphs.

\section{Main Results}

\subsection{F-Domination}

Let $K_{1, \mathrm{t}}$ be the star graph of order $(\mathrm{t}+1)$, the generalized star graph $\mathrm{P}(\mathrm{n}, \mathrm{t})$ is the graph obtained from $K_{1, \text { t }}$ by inserting exact $n-1$ vertices on each edge of $K_{1, \mathrm{t}}$, the generalized star graph $\mathrm{P}(\mathrm{n}, \mathrm{t})$ is shown in Fig. 1 .

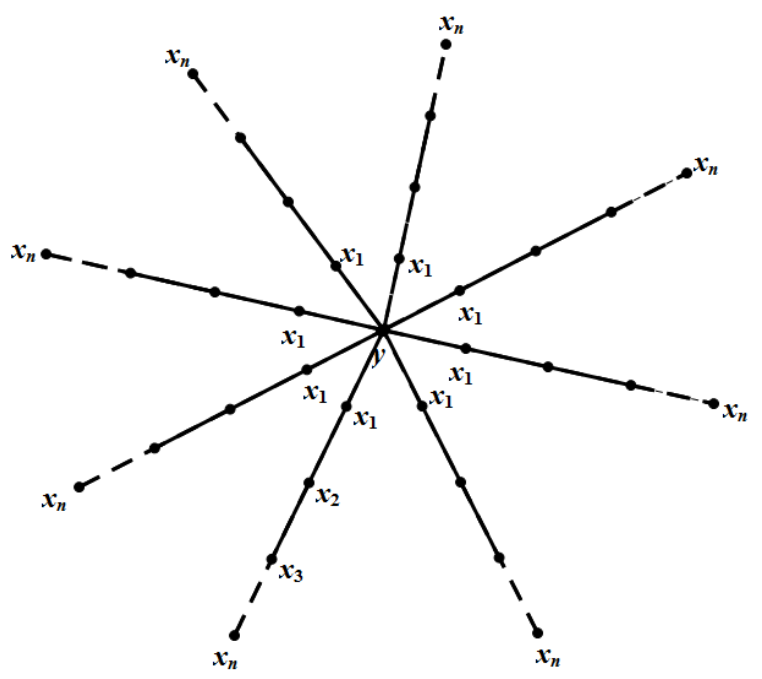

Fig. 1. The generalized star graph

Theorem 1 For the generalized star graph $P(\mathrm{n}, \mathrm{t})$ with $\mathrm{n} \geq 1$ and $\mathrm{t} \geq 3$, then

$$
\begin{aligned}
& \text { When } \mathrm{n} \equiv 0(\bmod 3), \gamma_{\mathrm{f}}\left(\mathrm{P}_{\mathrm{n}, \mathrm{t}}\right)=1+\frac{\mathrm{nt}}{3} \\
& \text { When } \mathrm{n} \equiv 1(\bmod 3), \gamma_{\mathrm{f}}\left(\mathrm{P}_{\mathrm{n}, \mathrm{t}}\right)=1+\left\lfloor\frac{\mathrm{n}}{3}\right\rfloor \mathrm{t} \\
& \text { When } \mathrm{n} \equiv 2(\bmod 3), \gamma_{\mathrm{f}}\left(\mathrm{P}_{\mathrm{n}, \mathrm{t}}\right)=\frac{(\mathrm{n}+1) \mathrm{t}}{3}
\end{aligned}
$$

Proof Let $V=V\left(P_{n}, t\right)$. See in Fig. 1, the labels of the vertices are shown in Fig. 1.

Define a function $\mathrm{f}: \mathrm{V} \rightarrow[0,1]$ as follows: let $\mathrm{f}\left(\mathrm{v}_{0}\right)=\mathrm{y}$, $f\left(v_{i j}\right)=x_{i}(j=1,2, \cdots, t)$.

Next we give the exact value of y and $x_{\mathrm{i}} \quad(\mathrm{i}=1,2, \cdots, \mathrm{n})$ as four cases.

Case 1 When $n=1$; From the equation $\left\{\begin{array}{l}y+t x=1 \\ y+x=1\end{array}\right.$ We can obtain $\left\{\begin{array}{l}\mathrm{x}=0 \\ \mathrm{y}=1\end{array}\right.$, then we have $\gamma_{f}\left(P_{1, \mathrm{t}}\right)=1$.

When $\mathrm{n}=2$; Similarly, we can obtain $\gamma_{f}\left(P_{2, \mathrm{t}}\right)=\mathrm{t}$.

Case 2 When $\mathrm{n} \equiv 0(\bmod 3)$; let $\mathrm{y}=1$, and for each integer $\mathrm{k}\left(0 \leq \mathrm{k} \leq \frac{\mathrm{n}}{3}-1\right)$,

$$
\text { let } \mathrm{x}_{3 \mathrm{k}+1}=0, \mathrm{x}_{3 \mathrm{k}+2}=0, \mathrm{x}_{3(\mathrm{k}+1)}=1 \text {. }
$$

It is easy to see that $f\left(N\left|\mathrm{v}_{\mathrm{ij}}\right|\right)=1$ holds for any vertex $\mathrm{v}_{\mathrm{i}, \mathrm{j}}$, and $0 \leq x_{i} \leq 1$ for every integer $i(i=1,2, \cdots, n)$ and $\mathrm{j}(\mathrm{j}=1,2, \cdots, \mathrm{t})$. By Lemma $2, f$ is a minimal $F$-dominating function, and hence, we have

$$
\gamma_{f}\left(P_{\mathrm{n}, \mathrm{t}}\right)=f(V)=y+t \sum_{\mathrm{i}=1}^{\mathrm{n}} \mathrm{x}_{\mathrm{i}}=1+\frac{\mathrm{nt}}{3} .
$$

Case 3 When $\mathrm{n} \equiv 1(\bmod 3)$; let $\mathrm{y}=1$, and for each integer $\mathrm{k}\left(0 \leq \mathrm{k} \leq \frac{\mathrm{n}}{3}-1\right)$,

$$
\text { let } \mathrm{x}_{3 \mathrm{k}+1}=0, \mathrm{x}_{3 \mathrm{k}+2}=0, \mathrm{x}_{3(\mathrm{k}+1)}=1, \mathrm{x}_{\mathrm{n}}=0 \text {. }
$$

Similar to Case 2, it is easy to see that $f\left(N\left|\mathrm{v}_{\mathrm{ij}}\right|\right)=1$ holds for any vertex $v_{i, j}$, and $0 \leq x_{i} \leq 1$ for every integer $\mathrm{i}(\mathrm{i}=1,2, \cdots, \mathrm{n})$ and $\mathrm{j}(\mathrm{j}=1,2, \cdots, \mathrm{t})$. By Lemma $2, f$ is a minimal $F$-dominating function, and hence, we have

$$
\gamma_{f}\left(P_{\mathrm{n}, \mathrm{t}}\right)=f(V)=y+t \sum_{\mathrm{i}=1}^{\mathrm{n}} \mathrm{x}_{\mathrm{i}}=1+\left\lfloor\frac{\mathrm{n}}{3}\right\rfloor \mathrm{t} .
$$

Case 4 When $\mathrm{n} \equiv 2(\bmod 3)$; let $\mathrm{y}=0$, and for each integer $\mathrm{k}\left(0 \leq \mathrm{k} \leq \frac{\mathrm{n}}{3}-1\right)$,

let

$$
\mathrm{x}_{3 \mathrm{k}+1}=\frac{1}{\mathrm{t}}, \mathrm{x}_{3 \mathrm{k}+2}=1-\frac{1}{\mathrm{t}}, \mathrm{x}_{3(\mathrm{k}+1)}=0, \mathrm{x}_{\mathrm{n}-1}=\frac{1}{\mathrm{t}}, \mathrm{x}_{\mathrm{n}}=1-\frac{1}{\mathrm{t}} .
$$

It is also easy to see that $f\left(N\left|v_{i j}\right|\right)=1$ for any vertex $v_{i, j}$, and note that $0 \leq x_{i} \leq 1$ for every integer $\mathrm{i}(\mathrm{i}=1,2, \cdots, \mathrm{n})$ and $\mathrm{j}(\mathrm{j}=1,2, \cdots, \mathrm{t})$. Similarly, $\mathrm{f}(\mathrm{N}[\mathrm{u}])=1$ holds for every $\mathrm{u} \in \mathrm{V}, f$ is the minimal $F$-dominating function, thus we have

$$
\gamma_{f}\left(P_{\mathrm{n}, \mathrm{t}}\right)=f(V)=y+t \sum_{\mathrm{i}=1}^{\mathrm{n}} \mathrm{x}_{\mathrm{i}}=\frac{(\mathrm{n}+1) \mathrm{t}}{3} .
$$


Combining the above four cases, we have completed the proof of Theorem 1. \#

\subsection{Fractional Total Domination}

Let $W_{1, \mathrm{t}}$ be a wheel graph of order $(\mathrm{t}+1)$. A generalized wheel graph $\mathrm{W}(\mathrm{n}, \mathrm{t})$ is shown in Fig.2.

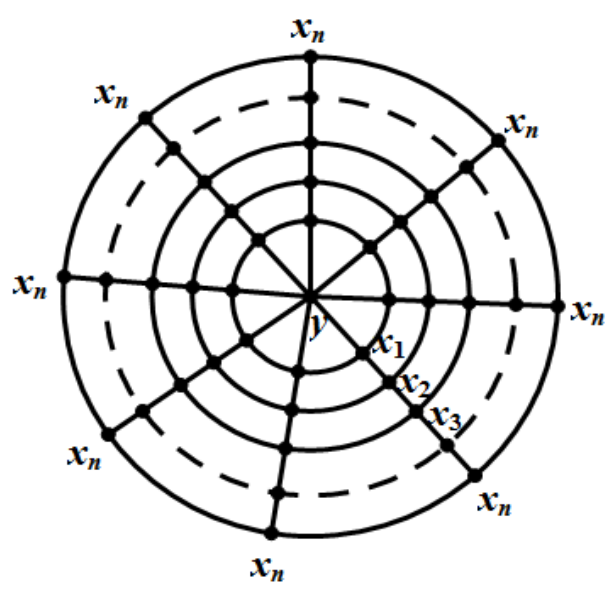

Fig 2. the generalized wheel graph

Theorem 2 For the generalized wheel graph $\mathrm{W}(\mathrm{n}, \mathrm{t})$ with $\mathrm{n} \geq 2$ and $\mathrm{t} \geq 3$, then

if $\mathrm{n}$ is odd,

$$
\gamma_{f}^{0}\left(W_{\mathrm{n}, \mathrm{t}}\right)=\frac{2\left(1+2+\cdots+\left\lfloor\frac{\mathrm{n}}{2}\right\rfloor\right) \mathrm{t}^{2}+(\mathrm{n}+1) \mathrm{t}-(\mathrm{n}+1)}{\mathrm{nt}}
$$

if $\mathrm{n}$ is even,

$$
\gamma_{f}^{0}\left(W_{\mathrm{n}, \mathrm{t}}\right)=\frac{\frac{\mathrm{n}^{2} \mathrm{t}^{2}}{4}+\mathrm{nt}-(\mathrm{n}+1)}{\mathrm{nt}} .
$$

Proof Let $V=V\left(W_{n, t}\right)$. Similar to the proof of Theorem 1 , and the labels $\mathrm{y}$ and $x_{\mathrm{i}}(1 \leq \mathrm{i} \leq \mathrm{n})$ of all vertices are shown in Fig. 2, define a function $f: V \rightarrow[0,1]$ as follows:

$$
\text { let } f\left(v_{0}\right)=y, f\left(v_{\mathrm{ij}}\right)=\mathrm{x}_{\mathrm{i}}(\mathrm{j}=1,2, \cdots, \mathrm{t}) \text {. }
$$

Case 1 When $\mathrm{n}=2 \mathrm{r}+1$ is odd ;

let $y=\frac{n+1}{2 n}-\frac{n+1}{n t}, x_{1}=\frac{1}{t}$, and for integer $i(1 \leq i \leq r)$,

$$
\text { let } x_{2 i}=\frac{n+1-2 i}{2 n}-\frac{n+1-2 i}{n t} \text { and } x_{2 i+1}=\frac{i}{n}+\frac{n-2 i}{n t} \text {. }
$$

It is easy to see that $\mathrm{f}\left(\mathrm{N}\left(\mathrm{v}_{\mathrm{ij}}\right)\right)=1$ holds for any vertex $v_{\mathrm{i}, \mathrm{j}}(1 \leq \mathrm{i} \leq \mathrm{n}, 1 \leq \mathrm{j} \leq \mathrm{t})$. Note that $0 \leq \mathrm{x}_{\mathrm{i}} \leq 1$ holds for each integer $\mathrm{i}(1 \leq \mathrm{i} \leq \mathrm{n})$. By Lemma $2, f$ is the minimal fractional total domination function. Thus we have

$$
\gamma_{f}^{0}\left(W_{\mathrm{n}, \mathrm{t}}\right)=f(V)=x_{0}+\mathrm{t} \sum_{\mathrm{i}=1}^{\mathrm{n}} \mathrm{x}_{\mathrm{i}}=\frac{2\left(1+2+\cdots+\left\lfloor\frac{\mathrm{n}}{2}\right\rfloor \mathrm{t}^{2}+(\mathrm{n}+1) \mathrm{t}-(\mathrm{n}+1)\right.}{\mathrm{nt}} .
$$

Case 2 When $\mathrm{n}=2 \mathrm{r}$ is even;

let $\mathrm{y}=\frac{1}{2}-\frac{\mathrm{n}+1}{\mathrm{nt}}$ and $\mathrm{x}_{1}=\frac{1}{\mathrm{t}}$, and for integer $\mathrm{i}(1 \leq \mathrm{i} \leq \mathrm{r})$

$$
\text { let } \mathrm{x}_{2 \mathrm{i}}=\frac{1}{2}-\frac{\mathrm{n}-2 \mathrm{i}+1}{\mathrm{nt}} \text { and } \mathrm{x}_{2 \mathrm{i}+1}=\frac{\mathrm{n}-2 \mathrm{i}}{\mathrm{nt}}
$$

Similarly to case 1 , it is also easy to see that $f\left(N\left(v_{i j}\right)\right)=1$ for any vertex $v_{\mathrm{i}, \mathrm{j}}(1 \leq \mathrm{i} \leq \mathrm{n}, 1 \leq \mathrm{j} \leq \mathrm{t})$, and $0 \leq \mathrm{x}_{\mathrm{i}} \leq 1$ holds for each integer $\mathrm{i}(1 \leq \mathrm{i} \leq \mathrm{n})$. By Lemma $2, f$ is the minimal fractional total domination function, so we have

$$
\gamma_{\mathrm{f}}^{0}\left(\mathrm{~W}_{\mathrm{n}, \mathrm{t}}\right)=\mathrm{f}(\mathrm{V})=\mathrm{x}_{0}+\mathrm{t} \sum_{\mathrm{i}=1}^{\mathrm{n}} \mathrm{x}_{\mathrm{i}}=\frac{\frac{\mathrm{n}^{2} \mathrm{t}^{2}}{4}+\mathrm{nt}-(\mathrm{n}+1)}{\mathrm{nt}}
$$

Combining the above three cases, we have completed the proof of Theorem 2. \#

\section{Acknowledgement}

This work is supported by the National Natural Science Foundation of China (11361024) and Jiangxi Science and Technology item (KJLD12067).

\section{References}

[1] Baogen $\mathrm{Xu}$. Theory of domination and coloring in graphs. Huazhong university of science and technology press, Wuhan, 2013

[2] Xiandi Zhang, Zhengliang Li. Graphs theory and its applications [M]. Peking: Higher education press,2005

[3] Bondy J A, Murty V S R. Graph theory with applications [M]. New York: Elsevier, 1976.

[4] G S Domke, S T Hedetniemi, R C Laskar. Fractional packings, coverings and irredundance in graphs [J]. Congr. Numer., 1988, 66: 227-238.

[5] T W Haynes, S T Hedetniemi, P J Slater. Domination in Graphs [M]. New York: Marcel Dekker Inc.1998. 